GU J Sci, Part C, 6(3): 621-633 (2018)

Gazi Üniversitesi
Fen Bilimleri Dergisi
PART C: TASARIM VE TEKNOLOJI
dergipark.gov.tr/gujsc

\title{
Yapay Sinir Ağları ile Şanlıurfa İstasyonunun Kuraklığının Tahmini
}

\author{
Veysel GÜMÜŞ ${ }^{1, *}$, Ahmet BAŞAK ${ }^{1}$, Kasım YENİGÜN ${ }^{1}$ \\ ${ }^{\text {I} H a r r a n ~ U ̈ n i v e r s i t e s i, ~ M u ̈ h e n d i s l i k ~ F a k u ̈ l t e s i, ~ I ̇ n s ̧ a a t ~ M u ̈ h e n d i s l i g ̆ i ~ B o ̈ l u ̈ m u ̈, ~ 63050, ~ H a l i l i y e / S ̧ A N L I U R F A ~}$
}

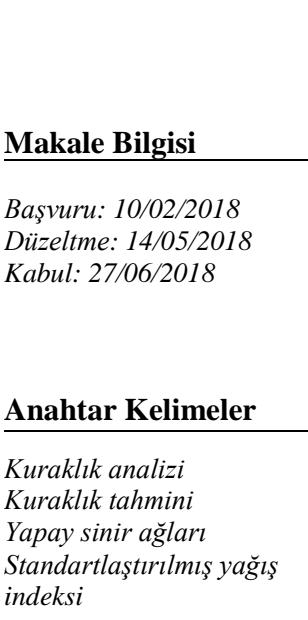

Keywords

Drought Analysis Drought estimation Artificial neural network Standardized precipitation index

\begin{abstract}
$\ddot{O} \mathbf{z}$
Kuraklığın erken tahmin edilmesi, kuraklığın olası olumsuz etkilerinin azaltılabilmesini sağlayabilir. Bu amaçla geliştirilen indisler ise geçmişe dönük kuraklığın belirlenmesini sağlamaktadır. Geçmiş dönemlere ait indis ve yağış verileri kullanılarak oluşması muhtemel kuraklığın tahmin edilmesi, erken uyarı sistemlerinin kurulabilmesine imkân tanıyabilecektir. $\mathrm{Bu}$ çalışmada, Şanlıurfa istasyonuna ait 1938-2014 yılları arasındaki yağış verileri ile hesaplanan Standartlaştırılmış Yağış İndeksi (SYİ) değerleri, geçmiş yağış ve kuraklık indisi değerleri kullanılarak tahmin edilmiştir. Kuraklığın tahmin edilmesinde İleri Beslemeli Geri Yayınımlı Yapay Sinir Ağı (İBGYSA) yöntemi kullanılmıştır. 1937-1990 yılları arasındaki geçmiş yağış ve kuraklık indisi verileri eğitim, 1991-2014 yılları arasındaki veriler ise test verisi olarak kullanılmıştır. 1, 3, 6 ve 12 aylık kuraklık indis değerlerinin tahmini için, her bir zaman ölçeğinde 16 model kullanılmıştır. Şanlıurfa istasyonu için 6 ve 12 aylık kuraklık indislerinin tahmininde yapay sinir ağları yönteminin uygulanabilir olduğu belirlenmiştir.
\end{abstract}

\section{Drought Estimation of Şanlıurfa Station with Artificial Neural Network}

\begin{abstract}
Early estimation of the drought may help reduce the potential adverse effects of drought. Indices developed for this purpose provide the information for the past drought events. Estimating the drought using indices and precipitation data from past periods should allow early warning systems to be established. In this study, the Standardized Precipitation Index (SPI) values calculated with the rainfall data of Şanlıurfa station between 1938-2014 years are estimated by using past rainfall and drought index values. Droughts are predicted using Feed Forward Back Propagation Neural Network (FFBPNN) method. The drought indices and precipitation values between 1937-1990 are used for training, and the values between 19912014 were used for test data. To estimation of 1, 3, 6 and 12 months drought index values, 16 models are used for each time scale. It has been determined that artificial neural network method is applicable for estimating 6 and 12 month SPI indexes for Şanlıurfa station.
\end{abstract}

\section{GÍRIŞ̧ (INTRODUCTION)}

Kuraklık, küresel ve yerel olarak birçok zarara neden olabilen, en yaygın görülen bir doğal afet türüdür. Kuraklık tahmini, kuraklığın olumsuz etkilerini en aza indirgemek için önemli bir rol oynamaktadır. Geleneksel olarak, kuraklığın tahmini için kuraklık indeksleri kullanılmaktadır. Bunun nedeni, kuraklık indekslerinin karar verme aşamasında ham verilerden çok daha işlevsel olan sayısal bir sayı ile ifade edilmesidir. Meteorolojik kuraklığın tanımlanması için birçok yöntem bulunmaktadır. Bunlardan en yaygın olanların Standartlaştırılmış Yağış İndeksi (SYİ) [1, 2], Etkin Kuraklık İndeksi (EKİ) [3] ve Palmer kuraklık şiddeti endeksi (PDSI) [4] yöntemleridir. Bu yöntemlerden SYİ ve EKİ değişken olarak sadece yağış verilerini kullanırken PDSI ise sıcaklığ 1 yağışla birlikte değerlendirerek kuraklık tahmininde bulunmaktadır.

Kuraklık indislerinin tahmin edilmesi ile ilgili literatürde birçok çalışma bulunmaktadır [5-15]. Bacanli ve ark. [5], çalışmalarında, İç Anadolu bölgesinde bulunan 10 Meteoroloji gözlem istasyonuna ait hesaplanmış olan SYİ değerlerini Adaptif Ağ Tabanlı Bulanık Mantık Çıkarım Sistemi( Adaptive Neuro- 
Fuzzy Inference System-ANFIS), İleri Beslemeli Geri Yayınımlı Sinir Ağı (İBGYSA) yöntemlerini kullanarak tahmin etmeye çalışmışlardır. Çalışmalarında zaman serisini eğitim ve test olmak üzere ikiye ayırmışlar ve çalışma sonucunda ANFIS yönteminin İBGYSA yöntemine göre kuraklık indisi tahmin etmede daha başarılı olduğu sonucuna varmışlardır. Mishra ve Desai [6], çalışmalarında SYİ değerlerini lineer stokastik modeller (ARIMA) ve Yapay Sinir Ağları (YSA) yöntemleri ile tahmin etmeye çalışmışlardır. Çalışma sonucunda ele alınan tüm yöntemlerin farklı zaman periyotları için kullanılabilir olduğu sonucuna varmışlardır. Keskin ve ark. [7], çalışmalarında 3, 6, 9 ve 12 aylık SYİ değerlerini ANFIS ve bulanık mantık yöntemleri ile tahmin etmeye çalışmışlardır. Çalışma sonucunda 12 aylık SYİ değerlerinin tahmininde ANFIS yönteminin bulanık mantık yönteminden daha iyi sonuç verdiğini görmüşlerdir. Bu çalışmaların yanı sıra yapay sinir ağları hidro-meteorolojik verilerin değerlendirilmesi amacıyla da sıklıkla kullanılmaktadır [16-19].

$\mathrm{Bu}$ çalışmanın amacı Şanlıurfa istasyonuna ait SYİ değerlerinin, geçmiş yağış ve SYİ indis verileri kullanılarak Yapay Sinir Ağları (YSA) ile tahmin edilmesidir. Bu sebeple, her zaman ölçeği için 16 farklı model oluşturulmuştur. Oluşturulan modellerde 1938-1990 yılları arasındaki veriler eğitim için kullanılmış, 1991-2014 yılları arasındaki veriler ise oluşturulmuş ağı test etmek amacıyla kullanılmışıı.

\section{MATERYAL VE YÖNTEM (MATERIAL AND METHOD)}

\section{1. Çalışma Alanı (Study Area)}

$\mathrm{Bu}$ çalışmada Türkiye'nin güney doğusunda yer alan ve 17270 numaralı Şanlıurfa istasyonu ele alınmıştır. (Şekil 1). Meteoroloji Genel Müdürlüğünden alınan, Şanlıurfa istasyonuna ait 78 yıllık (19372014) aylık yağış değerleri, bölgenin kuraklık analizinin hesabında kullanılmıştır. 17270 numaralı Şanlıurfa istasyonunun uzun yıllar ortalama yıllık yağış toplamı $459.9 \mathrm{~mm} / \mathrm{m}^{2}$, dir. Aylık bazda ise en düşük uzun yıllar ortalama toplam yağış değeri $0.59 \mathrm{~mm} / \mathrm{m}^{2}$ ile Temmuz ayında, en yüksek yağ 1 ş ise 89.8 $\mathrm{mm} / \mathrm{m}^{2}$ ile Ocak ayında meydana gelmektedir [20].

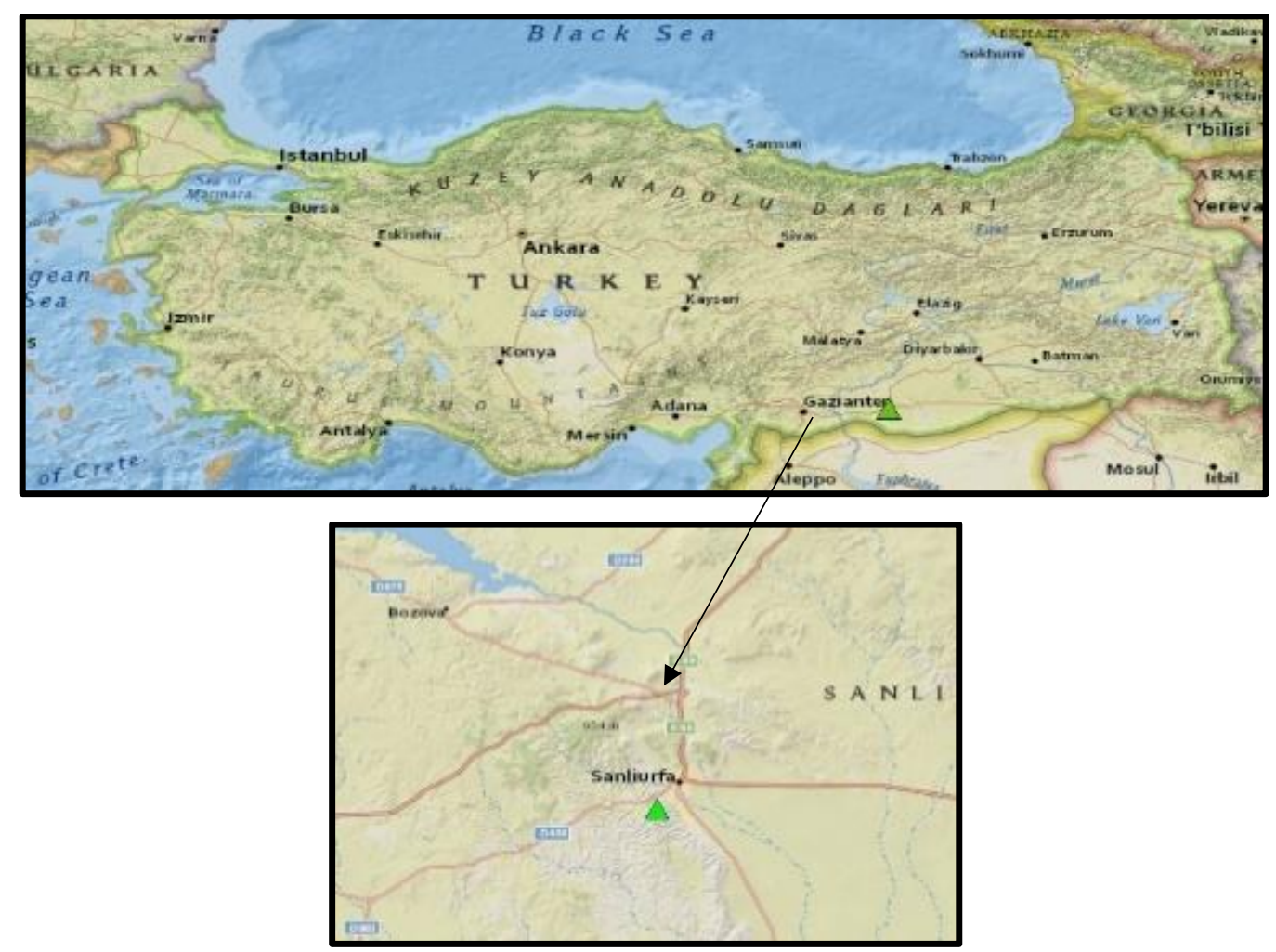

Şekil 1. Çalışma alanı 


\subsection{Yapay Sinir Ağları (YSA) (Artificial Neural Networks (ANN))}

Yapay sinir ağları (YSA), nöronların biyolojik modellerinden esinlenilerek geliştirilmiş paralel bilgi işleme yapılarıdır. YSA metotları içerisinde en çok kullanılanı hataların geriye yayılma (backpropagation) ilkesine göre çalışanıdır [21].

Üç katmanlı bir yapay sinir ağı modeli Şekil 2'de verilmiştir Burada görülen yapay sinir ağı modeli, her katmanda nöronların bulunduğu, girdi katmanı (i), gizli katman (j) ve çıktı katmanı (k) ile yapılandırılmıştır. Hücre katmanları arasındaki bağlantı ağırlıkları ise $A_{i j}$ ve $A_{j k}$ olarak ifade edilmiştir. Bağlantı ağırlık değerleri başlangıçta rastgele atanır ve eğitme sürecinde elde edilen çıktılarla gözlenen veya ölçülen gerçek çıktı değerleri karşılaştırılarak sürekli değiştirilir ve hataları en aza indirgeyecek bağlantı ağırlık değerlerine yakınsayana kadar hatalar geriye doğru yayılır. Bu çalışmada ağırlıkların ayarlanması için Levenberg-Marquardt yöntemi kullanılmıştır [22].

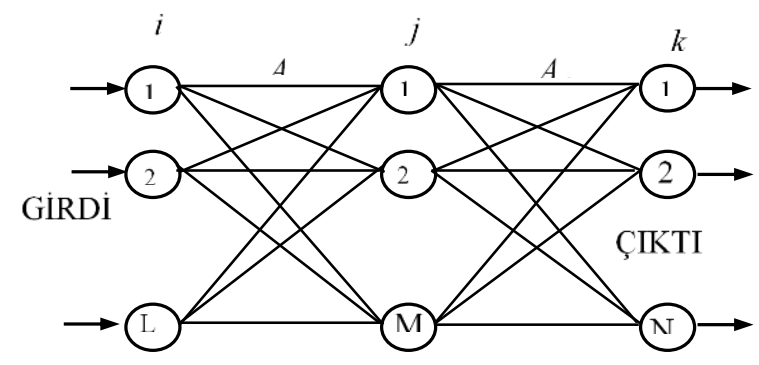

Şekil 2. Ü̧̧ tabakalı bir yapay sinir ă̆l.

\subsection{Model Performansının Belirlenmesi (Determination of Model Performance)}

Kuraklığın tahmini için hazırlanan model sonuçları, ortalama karesel hata (OKH), ortalama mutlak hata $(\mathrm{OMH})$ ve korelasyon katsayısı $(\mathrm{R})$ kriterlerine göre karşılaştırılmıştır. Bunlardan $\mathrm{OKH}$ ve $\mathrm{OMH}$ değerlerinin 0 'a, $\mathrm{R}$ değerinin 1'e yakın olması, tahmin edilen değerin kuvvetli biçimde doğruya yakınsadığını göstermektedir. Buna göre $\mathrm{N}$ toplam veri sayısı olmak üzere,

$$
\begin{aligned}
& \mathrm{OKH}=\frac{1}{N} \sum_{n=1}^{N}\left(S Y \dot{I}_{\text {hesap }}-S Y \dot{I}_{\text {tah } \min }\right)^{2} \\
& \mathrm{OMH}=\frac{1}{N} \sum_{n=1}^{N}\left|S Y \dot{I}_{\text {hesap }}-S Y \dot{I}_{\text {tah } \min }\right|
\end{aligned}
$$

şeklinde tanımlanırlar. Burada $S Y \dot{I}_{\text {hesap }}$, hesaplanan $S Y \dot{I}$ indis değerini, $S Y \dot{I}_{\text {tahmin }}$ ise model sonucunda elde edilen $S Y \dot{I}$ değerini ifade etmektedir.

\section{BULGULAR (RESULTS)}

Şanlıurfa istasyonuna ait geçmiş yağış ve SYİ değerlerine göre güncel SYİ değerlerinin tahmin edilmesi amaciyla 16 farklı durum için girdi verileri verilmiştir (Tablo 1). Tablo 1 içerisinde bulunan $\left(P_{(t-1)}, P_{(t-2)}\right.$, $\left.P_{(t-3)}, P_{(t-4)}, P_{(t-5)}, P_{(t-6)}\right)$ sırasıyla bir, iki, üç, dört, beş ve altı ay önceki yağış girdilerini, $S Y I_{(t-1)}$, $S Y I_{(t-2)}, S Y I_{(t-2)}, S Y I_{(t-3)}, S Y I_{(t-4)}, S Y I_{(t-4)}, S Y I_{(t-5)}, S Y I_{(t-6)}$ ise sırasıyla SYİ indisinin bir, iki, üç, dört, beş ve altı ay önceki değerini göstermektedir. $t$ anındaki SYİ değerini temsil eden $S Y I_{(t)}$ ise çıktı olarak tanımlanmıştır. Çalışma kapsamında Şanlıurfa istasyonuna ait 1938-1990 yılları arasındaki veriler eğitim sürecinde 1991-2014 yılları arasındaki veriler ise sadece test aşamasında kullanılmıştır. Test aşamasında kullanılan veriler eğitim sürecine dâhil edilmemiştir. 
Tablo 2'de 1 aylık kuraklık indis değerini ifade eden SYİ-1 değerlerinin Tablo 1'de verilen modellerle, YSA ile tahmin sonuçları verilmiştir. Buna göre, ele alınan yağış ve indis değerleri kullanılarak oluşturulan 16 modelde de SYİ-1 değerlerinin tahmin edilmesinde YSA başarısının düşük olduğu görülmektedir. Tüm modellere göre en yüksek korelasyon katsayıs1 test sürecinde 0.31 ile DM15'te görülmüş̧ür. Buna göre tüm modellerin SYİ-1 değerini tahmin etmede başarılı olmadığı anlaşılmaktadır.

Tablo 3'te 3 aylık kuraklık indis değerini ifade eden SYİ-3 değerlerinin YSA ile tahmin sonuçları verilmiştir. Buna göre, ele alınan modeller içerisinde sadece yağışın girdi olarak değerlendirildiği modellerin SYİ değerinin tahmin edilmesinde performansının düşük olduğu ve korelasyon katsayısının eğitim sürecinde 0.38 olsa da test sürecinde bu değerlerde ters korelasyon olarak karşımıza çıkmakta ve indisi tahmin etmede kullanılmayacağı sonucuna varılmaktadır. Girdi parametresi olarak sadece önceki indis değerlerinin olduğu DM07-DM12 arasındaki modellerde kuraklık indis tahmininin önceki modellere göre daha iyi olduğu ve test verilerinde korelasyon katsayısının 0.65 değerine kadar ulaştı̆̆ görülmektedir. Girdi parametresi olarak hem yağış hem de önceki indis değerlerinin olduğu DM13-DM16 arasındaki modellerde ise model başarısının oldukça arttığı ve korelasyon katsayısının eğitim verilerinde 0.75 , test verilerinde ise 0.70 değerine ulaştığı görülmektedir.

Tablo 1. SYİ Kuraklık indisinin belirlenmesinde kullanılan model girdileri ve çıktıları

\begin{tabular}{|l|l|l|}
\hline Model & \multicolumn{1}{|c|}{ Girdi } & Çıtı \\
\hline DM01 & $P_{(t-1)}$ & $S Y I_{(t)}$ \\
\hline DM02 & $P_{(t-1)}, P_{(t-2)}$ & $S Y I_{(t)}$ \\
\hline DM03 & $P_{(t-1)}, P_{(t-2)}, P_{(t-3)}$ & $S Y I_{(t)}$ \\
\hline DM04 & $P_{(t-1)}, P_{(t-2)}, P_{(t-3)}, P_{(t-4)}$ & $S Y I_{(t)}$ \\
\hline DM05 & $P_{(t-1)}, P_{(t-2)}, P_{(t-3)}, P_{(t-4)}, P_{(t-5)}$ & $S Y I_{(t)}$ \\
\hline DM06 & $P_{(t-1)}, P_{(t-2)}, P_{(t-3)}, P_{(t-4)}, P_{(t-5)}, P_{(t-6)}$ & $S Y I_{(t)}$ \\
\hline$D M 07$ & $S Y I_{(t-1)}$, & $S Y I_{(t)}$ \\
\hline$D M 08$ & $S Y I_{(t-1)}, S Y I_{(t-2)}$, & $S Y I_{(t)}$ \\
\hline$D M 09$ & $S Y I_{(t-1)}, S Y I_{(t-2)}, S Y I_{(t-3)}$ & $S Y I_{(t)}$ \\
\hline$D M 10$ & $S Y I_{(t-1)}, S Y I_{(t-2)}, S Y I_{(t-3)}, S Y I_{(t-4)}$ & $S Y I_{(t)}$ \\
\hline$D M 11$ & $S Y I_{(t-1)}, S Y I_{(t-2)}, S Y I_{(t-3)}, S Y I_{(t-4)}, S Y I_{(t-5)}$ & $S Y I_{(t)}$ \\
\hline$D M 12$ & $S Y I_{(t-1)}, S Y I_{(t-2)}, S Y I_{(t-3)}, S Y I_{(t-4)}, S Y I_{(t-5)}, S Y I_{(t-6)}$ & $S Y I_{(t)}$ \\
\hline DM13 & $S Y I_{(t-1)}, P_{(t-1)}$ & $S Y I_{(t)}$ \\
\hline DM14 & $S Y I_{(t-1)}, S Y I_{(t-2)}, P_{(t-1)}$ & $S Y I_{(t)}$ \\
\hline DM15 & $S Y I_{(t-1)}, S Y I_{(t-2)}, S Y I_{(t-3)}, P_{(t-1)}, P_{(t-1)}$ & $S Y I_{(t)}$ \\
\hline DM16 & $S Y I_{(t-1)}, S Y I_{(t-2)}, S Y I_{(t-3)}, S Y I_{(t-4)}, P_{(t-1)}, P_{(t-1)}, P_{(t-3)}$ & $S Y I_{(t)}$ \\
\hline
\end{tabular}

Tablo 4'te 6 aylık kuraklık indis değerini ifade eden SYİ-6 değerlerinin YSA ile tahmin sonuçları verilmiştir. Buna göre, ele alınan yağış ve indis değerleri kullanılarak oluşturulan modeller içerisinde sadece yağışın girdi olarak değerlendirildiği DM01-DM06 arasındaki modellerde indis değerinin tahmin edilmesinde, SYİ-3 değerlerine benzer bir şekilde, düşük olduğu görülmektedir. Girdi parametresi olarak önceki indis değerlerinin oluşturduğu DM07-DM12 arasındaki modellerde kuraklık indis tahmininde model başarısı açık bir şekilde artarak korelasyon katsayısı değeri eğitimde 0.85 , testte ise 0.76 değerlerine kadar yükselmektedir. Yağış ve önceki indis değerlerinin girdi olarak kullanıldığı DM13DM16 arasındaki modellerde ise model başarısının oldukça arttığı ve korelasyon katsayısının eğitim verilerinde 0.85 , test verilerinde ise 0.80 değerine ulaştığı, ayrıca $\mathrm{OMH}$ değerinin eğitim sürecinde 0.39 , test sürecinde ise 0.41 değerine düştüğü belirlenmiştir. 
Tablo 2. SYİ-1 değerlerinin YSA yöntemine göre eğitim ve test sonuçlarının $R, O K H$ ve OMH değerleri

\begin{tabular}{|l|l|l|l|l|l|l|}
\hline \multirow{2}{*}{ Model } & \multicolumn{3}{|c|}{ Eğitim } & \multicolumn{3}{|c|}{ Test } \\
\cline { 2 - 7 } & R & OKH & OMH & R & OKH & OMH \\
\hline DM01 & 0.22 & 0.76 & 0.67 & 0.19 & 0.96 & 0.75 \\
\hline DM02 & 0.29 & 0.74 & 0.64 & 0.23 & 0.95 & 0.74 \\
\hline DM03 & 0.42 & 0.66 & 0.61 & 0.25 & 0.96 & 0.74 \\
\hline DM04 & 0.34 & 0.71 & 0.64 & 0.28 & 0.92 & 0.72 \\
\hline DM05 & 0.33 & 0.72 & 0.65 & 0.29 & 0.92 & 0.73 \\
\hline DM06 & 0.42 & 0.66 & 0.63 & 0.28 & 0.93 & 0.72 \\
\hline DM07 & 0.24 & 0.75 & 0.67 & 0.19 & 0.97 & 0.75 \\
\hline DM08 & 0.30 & 0.73 & 0.66 & 0.16 & 1.03 & 0.78 \\
\hline DM09 & 0.15 & 0.78 & 0.69 & 0.14 & 0.98 & 0.76 \\
\hline DM10 & 0.28 & 0.74 & 0.67 & 0.13 & 1.02 & 0.76 \\
\hline DM11 & 0.46 & 0.63 & 0.60 & 0.12 & 1.10 & 0.79 \\
\hline DM12 & 0.46 & 0.63 & 0.62 & 0.15 & 1.05 & 0.77 \\
\hline DM13 & 0.40 & 0.68 & 0.61 & 0.27 & 0.94 & 0.71 \\
\hline DM14 & 0.39 & 0.68 & 0.61 & 0.29 & 0.93 & 0.71 \\
\hline DM15 & 0.44 & 0.65 & 0.60 & 0.31 & 0.91 & 0.72 \\
\hline DM16 & 0.43 & 0.65 & 0.58 & 0.29 & 0.93 & 0.71 \\
\hline
\end{tabular}

Tablo 3. SYİ-3 değerlerinin YSA yöntemine göre eğitim ve test sonuçlarının R, OKH ve OMH değerleri

\begin{tabular}{|l|l|l|l|l|l|l|}
\hline \multirow{2}{*}{ Model } & \multicolumn{3}{|c|}{ Ĕgitim } & \multicolumn{3}{c|}{ Test } \\
\cline { 2 - 7 } & R & OKH & OMH & R & OKH & OMH \\
\hline DM01 & 0.17 & 0.86 & 0.72 & -0.11 & 1.05 & 0.81 \\
\hline DM02 & 0.20 & 0.85 & 0.72 & -0.13 & 1.08 & 0.83 \\
\hline DM03 & 0.29 & 0.81 & 0.70 & -0.06 & 1.10 & 0.83 \\
\hline DM04 & 0.21 & 0.85 & 0.72 & -0.13 & 1.10 & 0.83 \\
\hline DM05 & 0.26 & 0.83 & 0.70 & -0.14 & 1.13 & 0.84 \\
\hline DM06 & 0.38 & 0.76 & 0.68 & -0.01 & 1.14 & 0.84 \\
\hline DM07 & 0.65 & 0.51 & 0.55 & 0.58 & 0.67 & 0.63 \\
\hline DM08 & 0.65 & 0.52 & 0.55 & 0.59 & 0.66 & 0.62 \\
\hline DM09 & 0.64 & 0.53 & 0.56 & 0.63 & 0.61 & 0.60 \\
\hline DM10 & 0.70 & 0.45 & 0.51 & 0.65 & 0.59 & 0.58 \\
\hline DM11 & 0.74 & 0.40 & 0.49 & 0.60 & 0.65 & 0.61 \\
\hline DM12 & 0.75 & 0.39 & 0.48 & 0.61 & 0.64 & 0.62 \\
\hline DM13 & 0.73 & 0.41 & 0.48 & 0.64 & 0.60 & 0.57 \\
\hline DM14 & 0.73 & 0.42 & 0.48 & 0.62 & 0.63 & 0.57 \\
\hline DM15 & 0.75 & 0.39 & 0.47 & 0.69 & 0.53 & 0.55 \\
\hline DM16 & 0.75 & 0.39 & 0.46 & 0.70 & 0.52 & 0.52 \\
\hline
\end{tabular}

Tablo 4. SYİ-6 değerlerinin YSA yöntemine göre eğitim ve test sonuçlarının R, OKH ve OMH değerleri

\begin{tabular}{|l|l|l|l|l|l|l|}
\hline \multirow{2}{*}{ Model } & \multicolumn{3}{|c|}{ Ĕgitim } & \multicolumn{3}{c|}{ Test } \\
\cline { 2 - 7 } & $\mathbf{R}$ & OKH & OMH & R & OKH & OMH \\
\hline DM01 & 0.13 & 1.02 & 0.77 & 0.05 & 0.91 & 0.75 \\
\hline DM02 & 0.13 & 1.02 & 0.77 & -0.07 & 0.93 & 0.76 \\
\hline DM03 & 0.32 & 0.93 & 0.74 & -0.03 & 1.04 & 0.80 \\
\hline DM04 & 0.10 & 1.03 & 0.78 & -0.04 & 0.92 & 0.75 \\
\hline DM05 & 0.24 & 0.98 & 0.77 & 0.05 & 0.94 & 0.76 \\
\hline DM06 & 0.36 & 0.90 & 0.72 & 0.05 & 0.97 & 0.78 \\
\hline DM07 & 0.79 & 0.39 & 0.46 & 0.74 & 0.40 & 0.48 \\
\hline DM08 & 0.79 & 0.38 & 0.46 & 0.76 & 0.38 & 0.46 \\
\hline DM09 & 0.74 & 0.48 & 0.52 & 0.73 & 0.41 & 0.48 \\
\hline DM10 & 0.79 & 0.38 & 0.46 & 0.76 & 0.38 & 0.46 \\
\hline DM11 & 0.83 & 0.32 & 0.42 & 0.75 & 0.39 & 0.47 \\
\hline DM12 & 0.85 & 0.29 & 0.40 & 0.74 & 0.41 & 0.47 \\
\hline DM13 & 0.85 & 0.30 & 0.40 & 0.79 & 0.34 & 0.43 \\
\hline DM14 & 0.84 & 0.30 & 0.41 & 0.80 & 0.32 & 0.42 \\
\hline DM15 & 0.85 & 0.29 & 0.40 & 0.81 & 0.32 & 0.41 \\
\hline DM16 & 0.85 & 0.29 & 0.39 & 0.81 & 0.32 & 0.41 \\
\hline
\end{tabular}


Tablo 5'te 12 aylık kuraklık indis değerini ifade eden SYİ-12 değerlerinin YSA ile tahmin sonuçları verilmiştir. Buna göre, SYİ-12 değerlerinin tahmininde de SYİ indisinin diğer zaman ölçeklerine benzer bir şekilde ele alınan yağış ve indis değerleri kullanılarak oluşturulan modeller içerisinde sadece yağışın girdi olarak değerlendirildiği DM01-DM06 arasındaki modellerde indis değerinin tahmin edilmesinde başarılı olmadığı görülmektedir DM07-DM12 arasındaki modellerde kuraklık indis tahmininde model başarısı açık bir şekilde artarak korelasyon katsayısının DM12 için eğitimde 0.94, testte 0.87 değerine ulaştığı, ayrıca $\mathrm{OMH}$ değerinin de eğitim ve test için sırasıyla 0.25 ile 0.32 olduğu görülmektedir. Yağış ve önceki indis değerlerinin tahminde kullanıldığı modellerde ise DM16'nın oldukça başarılı sonuçlar verdiği tablodan anlaşılmaktadır. Burada korelasyon katsayısı eğitimde 0.95 , testte 0.93 , OMH değeri ise eğitimde 0.21 , testte ise 0.23 olmaktadır.

Tablo 5. SYI-12 değerlerinin YSA yöntemine göre eğitim ve test sonuçlarının R, OKH ve OMH değerleri

\begin{tabular}{|l|l|l|l|l|l|l|}
\hline \multirow{2}{*}{ Model } & \multicolumn{3}{|c|}{ Eğitim } & \multicolumn{3}{c|}{ Test } \\
\cline { 2 - 7 } & R & OKH & OMH & R & OKH & OMH \\
\hline DM01 & 0.10 & 1.02 & 0.73 & -0.01 & 0.99 & 0.78 \\
\hline DM02 & 0.17 & 1.00 & 0.72 & 0.00 & 1.01 & 0.80 \\
\hline DM03 & 0.20 & 0.99 & 0.73 & 0.04 & 1.00 & 0.79 \\
\hline DM04 & 0.13 & 1.01 & 0.73 & 0.02 & 1.00 & 0.79 \\
\hline DM05 & 0.21 & 0.99 & 0.73 & 0.00 & 1.03 & 0.81 \\
\hline DM06 & 0.35 & 0.90 & 0.69 & -0.07 & 1.14 & 0.83 \\
\hline DM07 & 0.93 & 0.15 & 0.26 & 0.89 & 0.18 & 0.29 \\
\hline DM08 & 0.93 & 0.14 & 0.25 & 0.89 & 0.19 & 0.29 \\
\hline DM09 & 0.85 & 0.35 & 0.38 & 0.86 & 0.27 & 0.35 \\
\hline DM10 & 0.93 & 0.14 & 0.25 & 0.89 & 0.19 & 0.30 \\
\hline DM11 & 0.94 & 0.12 & 0.24 & 0.88 & 0.21 & 0.32 \\
\hline DM12 & 0.94 & 0.13 & 0.25 & 0.87 & 0.21 & 0.32 \\
\hline DM13 & 0.96 & 0.09 & 0.20 & 0.89 & 0.19 & 0.27 \\
\hline DM14 & 0.95 & 0.10 & 0.21 & 0.93 & 0.12 & 0.24 \\
\hline DM15 & 0.95 & 0.09 & 0.21 & 0.93 & 0.12 & 0.24 \\
\hline DM16 & 0.95 & 0.10 & 0.21 & 0.93 & 0.12 & 0.23 \\
\hline
\end{tabular}

Dört farklı zaman ölçeğine göre DM06, DM12 ve DM16 için saçılma grafikleri Şekil 3, 4, 5 ve 6'da verilmiştir. Buradan SYİ-1 dışındaki indislerin tahmininde girdi parametresi olarak önceki indis değerlerinin hesaplamaya alınması sonucunda model başarısının bariz bir şekilde arttığı görülmektedir. Şekil 3'te SYİ-1 değerlerinin üç farklı modele göre saçılım diyagramları eğitim ve test için verilmiştir. Buna göre, YSA yönteminin, yağışın, önceki indis değerlerinin ya da her ikisinin de girdi parametresi olarak oluşturulan modellerde SYİ-1 kuraklık indisinin tahmininde yetersiz kaldığı görülmüsstür. 


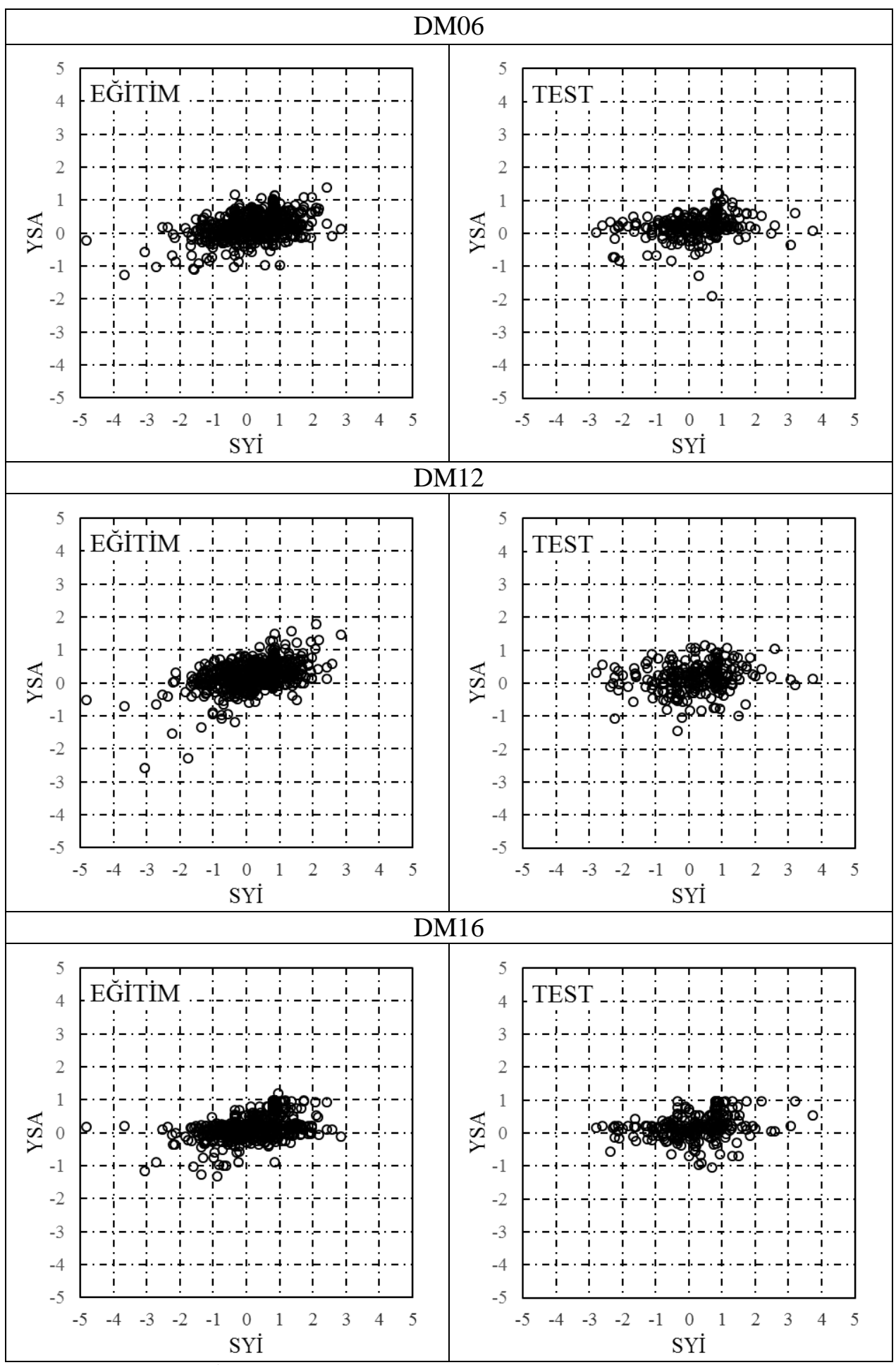

Şekil 3. SYİ-1 için üç farklı durumda elde edilen saçılım grafikleri

Sırasıyla Şekil 4 (A), 4 (B) ve Şekil 5'te verilen SYİ-3, SYİ-6 ve SYİ-12 değerlerinin tahmininde ise sadece yağış parametrelerinin girdi olarak tanımlandığı modellerde, modelin tahmin yeteneğinin oldukça yetersiz kaldığ görülmüştür. Ancak SYİ'in geçmiş değerlerinin girdi parametresi olarak eklendiği durumlarda model performansının oldukça geliştiği grafiklerden anlaşılmaktadır. Hem yağış, hem de önceki kuraklık indis parametresinin girdi olarak değerlendirildiği DM16 durumunda ise en iyi tahmin durumu ortaya çıkmaktadır. 


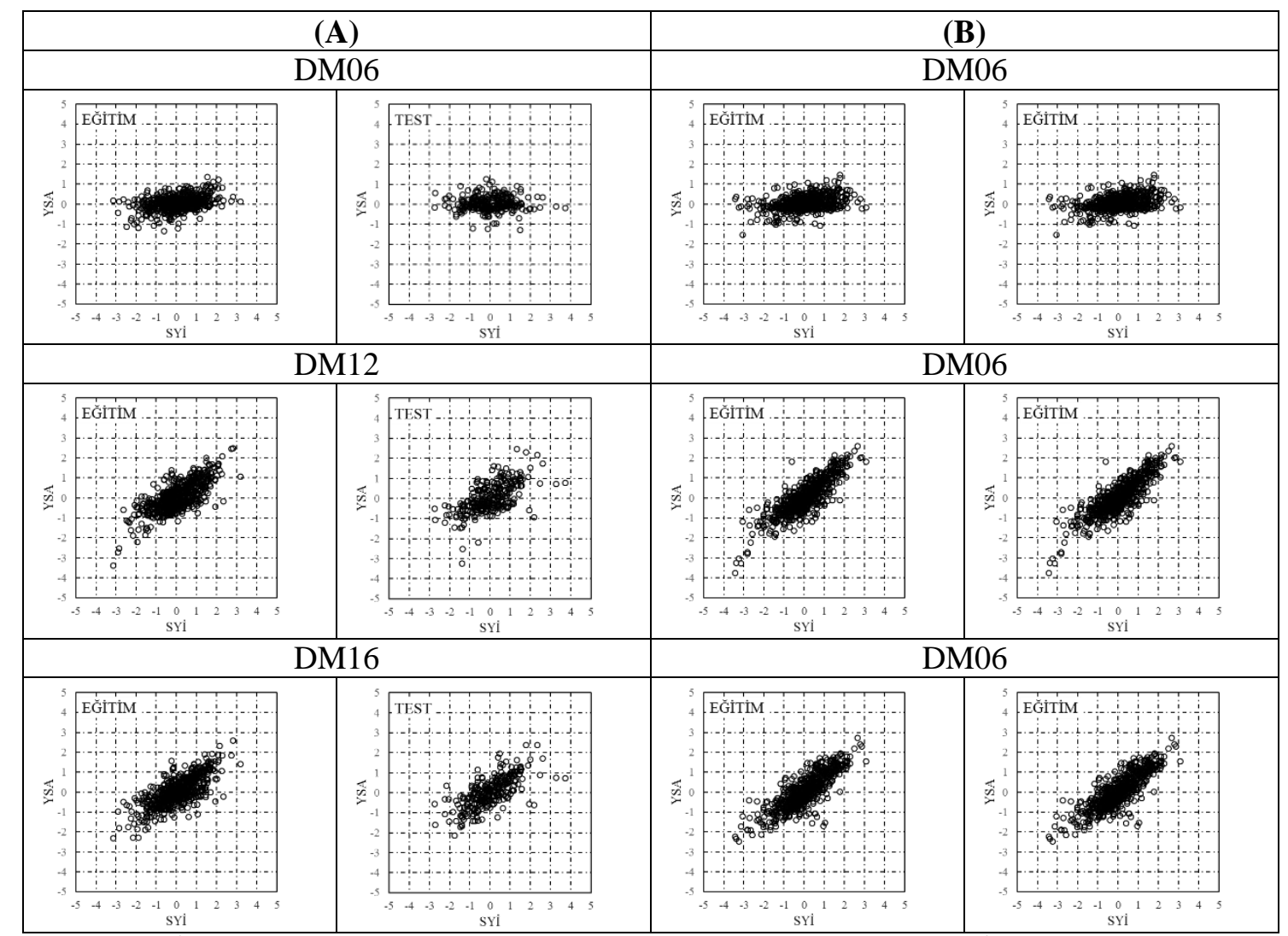

Şekil 4. A) SYİ-3 için üç farklı durumda elde edilen saçılım grafikleri B) SYİ-6 için üç farklı durumda elde edilen saçılım grafikleri

Şekil 6, 7 ve 8'de sırasıyla SYİ-3, SYİ-6 ve SYİ-12 için DM16 ile tahmin edilen indis değerlerinin zamansal dağılımları bulunmaktadır. Burada, özellikle SYİ-6 ve SYİ-12 indis değerlerinin eğitim ve test süreçlerinde tahmin etme performansının yüksek olduğu anlaşılmaktadır. 


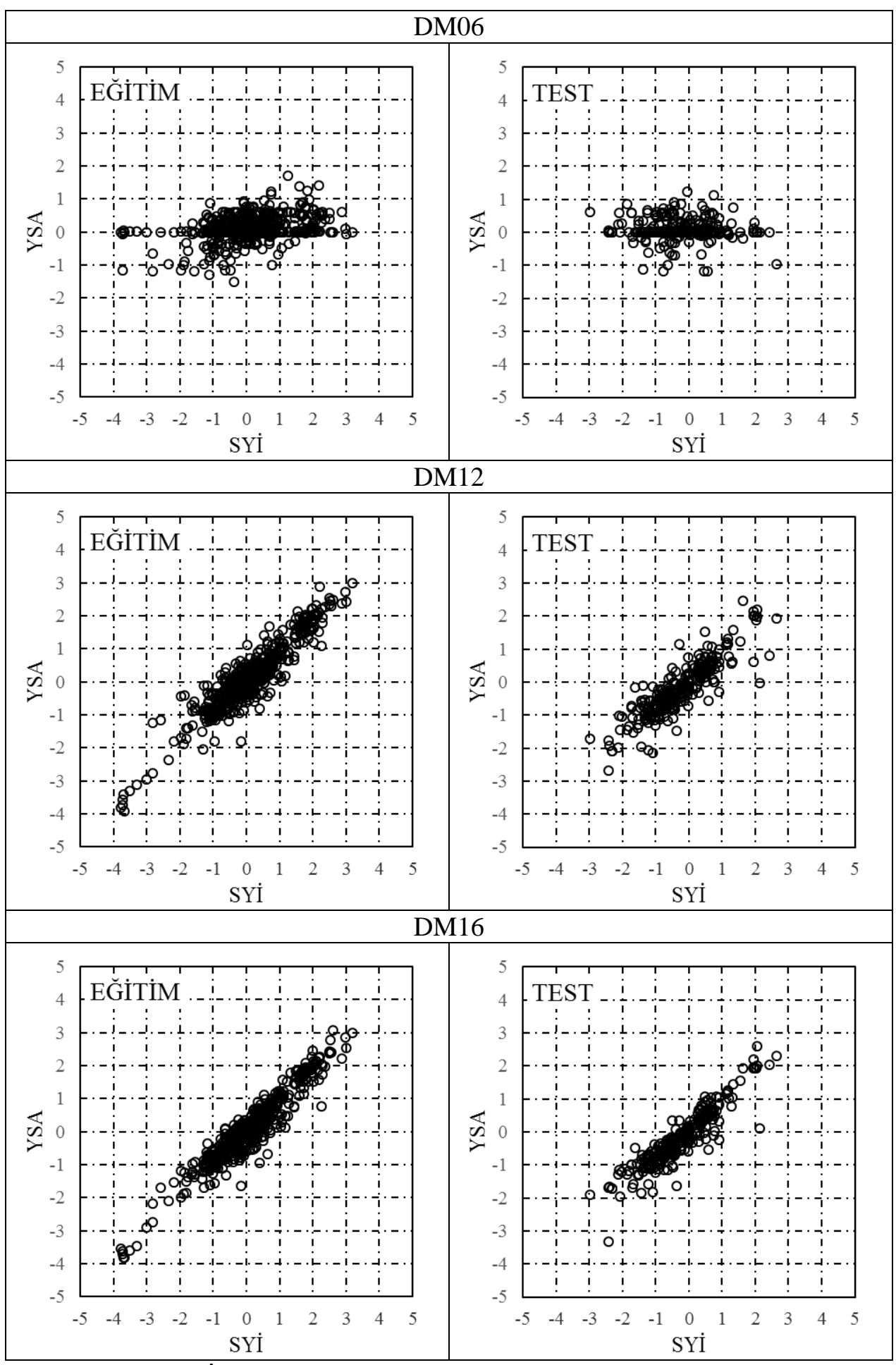

Şekil 5. SYİ-12 için üç farklı durumda elde edilen saçılım grafikleri 

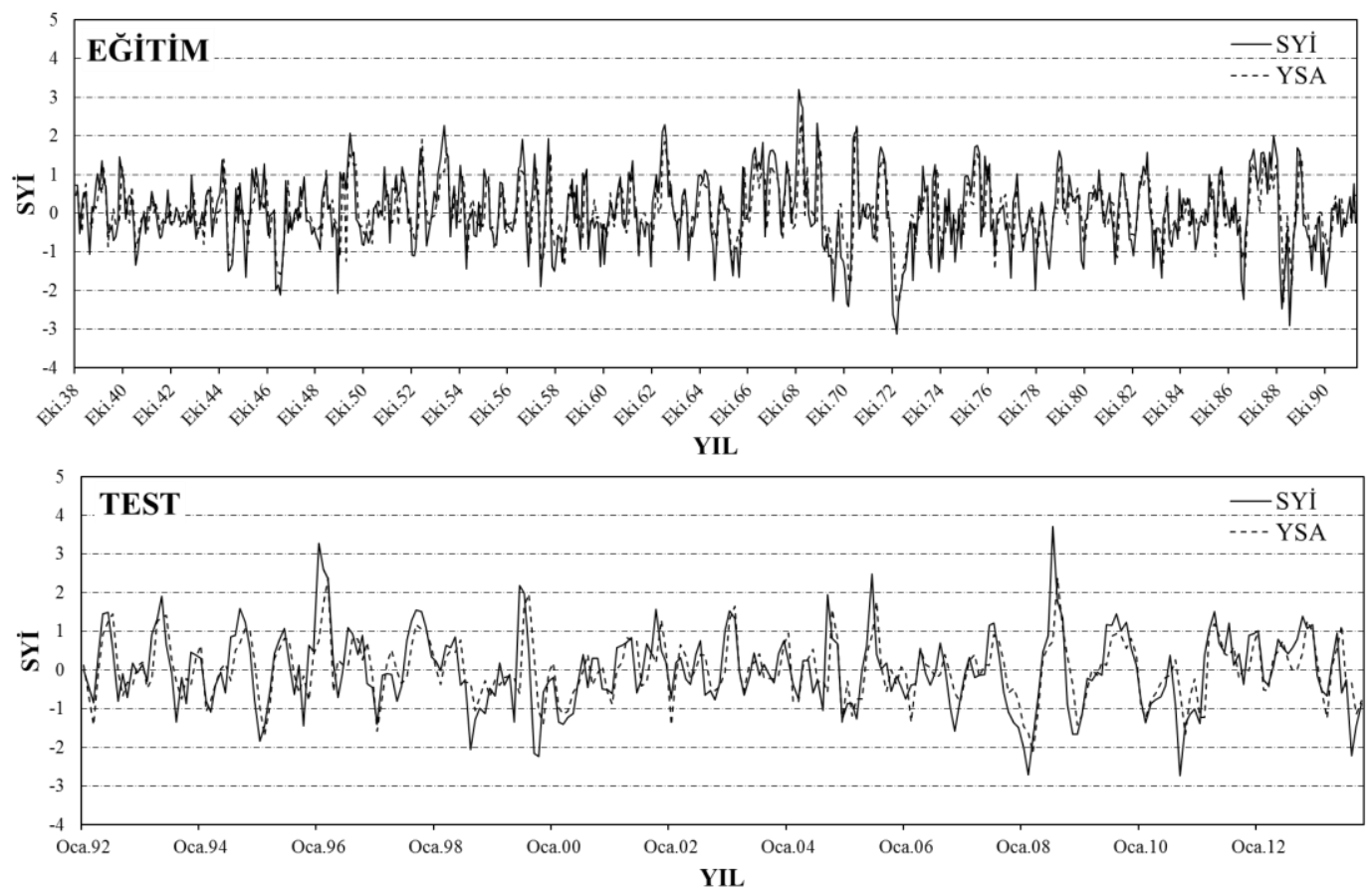

Şekil 6. SYİ-3 için DM16 ile elde edilen SYI değerleri
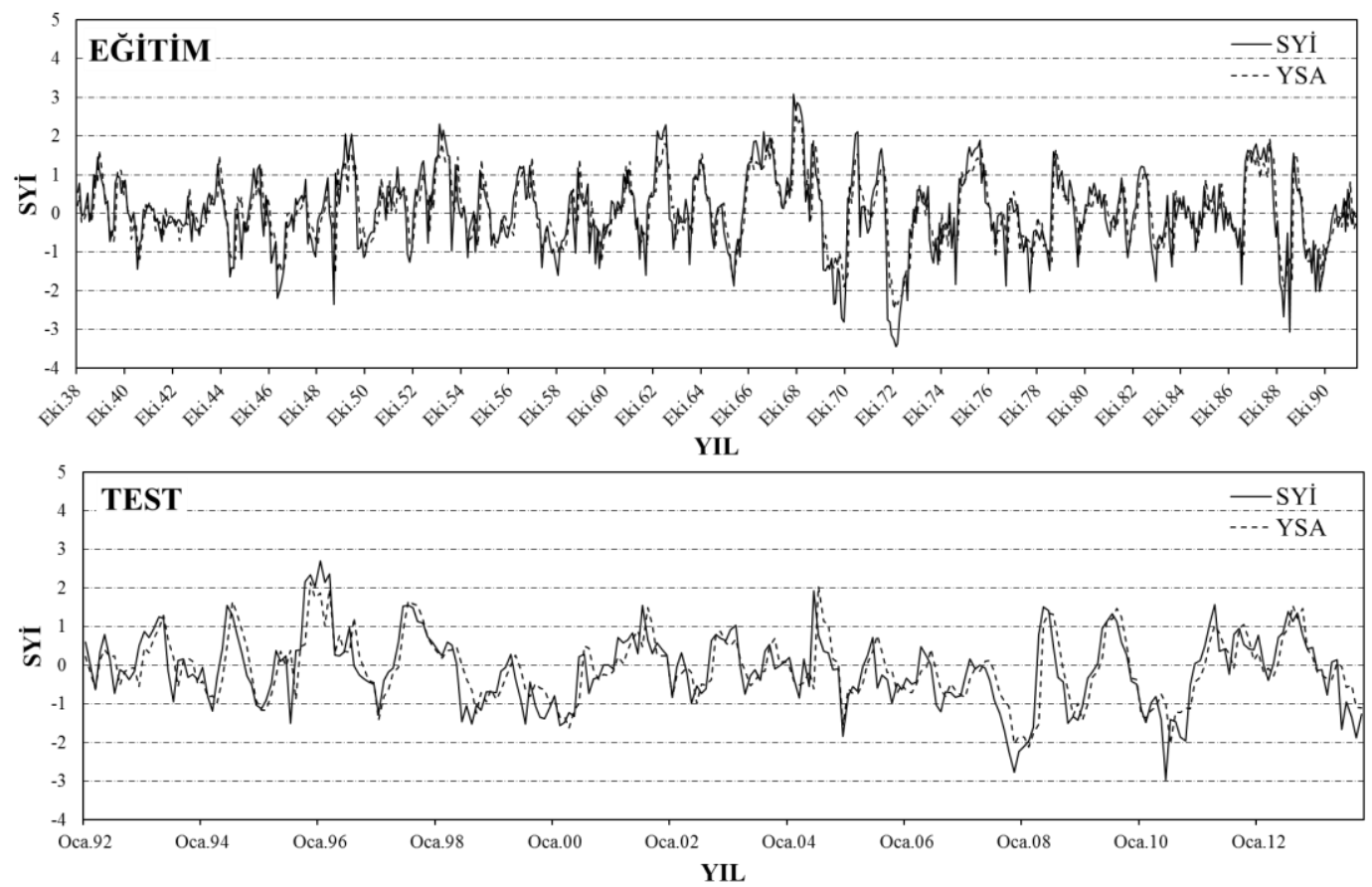

Şekil 7. SYİ-6 için DM16 ile elde edilen SYİ değerleri 

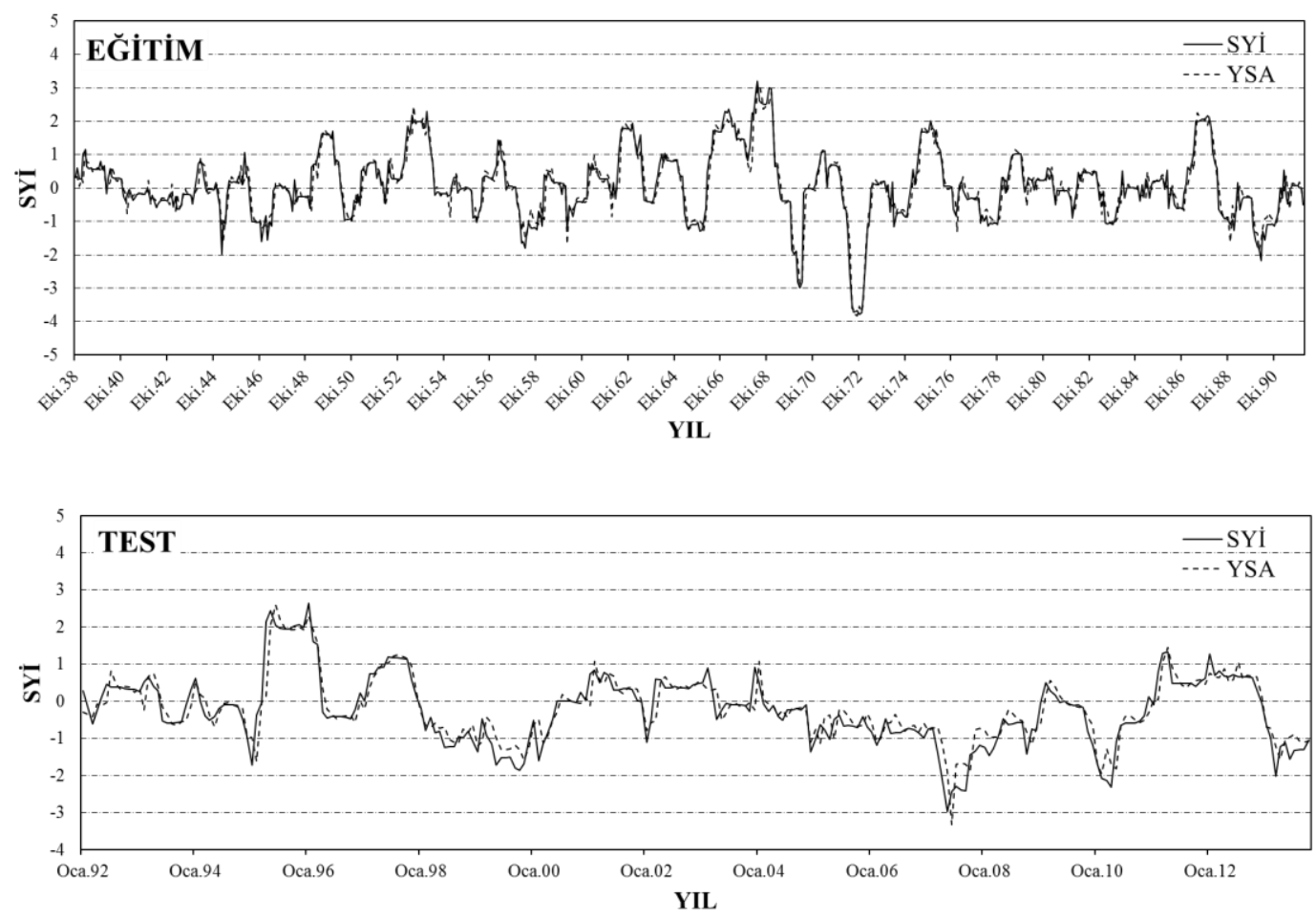

Şekil 8. SYİ-12 için DM16 ile elde edilen SYİ değerleri

Çalışma kapsamında elde edilen sonuçlar incelendiğinde, kuraklık indisinin tahmininde en başarılı sonuçları geçmiş indis değerleri ve geçmiş yağış değerleri kullanılarak oluşturulan modellerde elde edilmiştir, bu bulgu Bacanli ve ark. [5], Morid ve ark. [15] tarafından yapılan çalışma sonuçları ile uyumludur. Bunun yanında, SYİ-12 değerlerinin tahmin edilmesinde model performansı daha başarılı olduğu belirlenmiş olup, bu sonuçlar Keskin ve ark. [7] tarafindan yapılmış olan çalışma ile uyumludur. Keskin ve ark. [7] tarafindan oluşturulan modeller ile 12 aylık SYİ değerlerinin tahmin edilmesinde model performansı 3, 6 ve 9 aylık SYİ değerlerinin tahmininden daha yüksek olduğunu belirlemişlerdir.

\section{SONUÇ (CONCLUSION)}

Şanlıurfa istasyonuna ait hesaplanmış Standartlaştırılmış Yağış İndeksi (SYİ) değerlerinin yağış ve önceki indis değerleri kullanılarak tahmin edilmesi amacıyla yapay sinir ağları (YSA) kullanılarak 16 model oluşturulmuştur. SYİ-1 değerlerinin tahmininde oluşturulan tüm modeller SYİ-1'i tahmin etmede oldukça yetersiz kalmışlardır. 3, 6 ve 12 aylık SYİ tahmininde ise sadece yağışın girdi olarak kullanıldığı modellerin tahmin performansının düşük olduğu, ancak özellikle önceki kuraklık indisi değerlerinin eklenmesiyle oluşturulan modellerde kuraklık indisi tahmininin daha başarılı olduğu görülmüştür. Çalışma sonucunda kurulan tüm modeller içerisinde DM16 modeli ile tahmin edilen SYİ değerleri içerisinde test sürecinde elde edilen en yüksek korelasyon katsayısı değeri 0.93 ile SYİ-12 değerlerinin tahmininde bulunmuştur. DM16 için test sürecinde elde edilen korelasyon katsayısı değerleri SYİ-1, SYİ3 ve SYİ-6 için sırasıyla $0.29,0.70$ ve 0.81 olarak belirlenmiştir.

Özellikle kuraklığın önceden tahmin edilmesi, kuraklığın olası olumsuz etkilerini en aza indirmek için gerekli önlemlerin alınması oldukça önemlidir. Bundan dolayı, kuraklığın tahmin edilmesinde modern hesaplama yöntemlerinin kullanımının arttırılması ve farklı bölgelerde uygulanabilirliğinin araştırılması ile ilgili çalışmaların arttıılması, uygulayıcıların bilgi vermesi açısından yararlı olacaktır. 


\section{TEŞEKKÜR (ACKNOWLEDGMENTS)}

$\mathrm{Bu}$ çalışma Harran Üniversitesi Bilimsel Araştırma Projeleri Komisyonu (HÜBAK) tarafından 15107 numaralı proje kapsamında desteklenmiştir.

\section{KAYNAKLAR (REFERENCES)}

[1] Mckee, T.B., Doesken, N.J., ve Kleist, J. The relationship of drought frequency and duration to time scales. in Proceedings of the 8th Conference on Applied Climatology. 1993. American Meteorological Society Boston, MA, USA.

[2] Gumus, V. ve Algin, H.M., Meteorological and hydrological drought analysis of the Seyhan-Ceyhan River Basins, Turkey. Meteorological Applications, 2017. 24(1): p. 62-73.

[3] Byun, H.-R. ve Wilhite, D.A., Objective Quantification of Drought Severity and Duration. Journal of Climate, 1999. 12(9): p. 2747-2756.

[4] Palmer, W.C., Meteorological drought. Vol. 30. 1965: US Department of Commerce, Weather Bureau Washington, DC, USA.

[5] Bacanli, U.G., Firat, M., ve Dikbas, F., Adaptive Neuro-Fuzzy Inference System for drought forecasting. Stochastic Environmental Research and Risk Assessment, 2008. 23(8): p. 1143-1154.

[6] Mishra, A.K. ve Desai, V.R., Drought forecasting using feed-forward recursive neural network. Ecological Modelling, 2006. 198(1-2): p. 127-138.

[7] Keskin, M.E., Terzi, Ö., Taylan, E.D., ve Küçükyaman, D., Meteorological drought analysis using data-driven models for the Lakes District, Turkey. Hydrological Sciences Journal, 2009. 54(6): p. 1114-1124.

[8] Ali, Z., Hussain, I., Faisal, M., Nazir, H.M., Hussain, T., Shad, M.Y., Mohamd Shoukry, A., ve Hussain Gani, S., Forecasting Drought Using Multilayer Perceptron Artificial Neural Network Model. Advances in Meteorology, 2017. 2017: p. 1-9.

[9] Ali, M., Deo, R.C., Downs, N.J., ve Maraseni, T., An ensemble-ANFIS based uncertainty assessment model for forecasting multi-scalar standardized precipitation index. Atmospheric Research, 2018. 207: p. 155-180.

[10] Mokhtarzad, M., Eskandari, F., Jamshidi Vanjani, N., ve Arabasadi, A., Drought forecasting by $A N N$, ANFIS, and SVM and comparison of the models. Environmental Earth Sciences, 2017. 76(21).

[11] Hosseini-Moghari, S.-M., Araghinejad, S., ve Azarnivand, A., Drought forecasting using datadriven methods and an evolutionary algorithm. Modeling Earth Systems and Environment, 2017. 3(4): p. 1675-1689.

[12] Deo, R.C., Kisi, O., ve Singh, V.P., Drought forecasting in eastern Australia using multivariate adaptive regression spline, least square support vector machine and M5Tree model. Atmospheric Research, 2017. 184: p. 149-175.

[13] Belayneh, A., Adamowski, J., Khalil, B., ve Ozga-Zielinski, B., Long-term SPI drought forecasting in the Awash River Basin in Ethiopia using wavelet neural network and wavelet support vector regression models. Journal of Hydrology, 2014. 508: p. 418-429.

[14] Barua, S., Ng, A.W.M., ve Perera, B.J.C., Artificial Neural Network-Based Drought Forecasting Using a Nonlinear Aggregated Drought Index. Journal of Hydrologic Engineering, 2012. 17(12): p. $1408-1413$.

[15] Morid, S., Smakhtin, V., ve Bagherzadeh, K., Drought forecasting using artificial neural networks and time series of drought indices. International Journal of Climatology, 2007. 27(15): p. 21032111.

[16] Gümüş, V., Soydan, N.G., Şimşek, O., Aköz, M.S., ve Kırkgöz, M.S., Yağış-Akış İlişkisinin Belirlenmesinde Farklı Yapay Sinir A $\breve{g ̆}_{\imath}$ Yöntemlerinin Karşılaştırılması. Çukurova Üniversitesi Mühendislik Mimarlık Fakültesi Dergisi, 2013. 28(1): p. 37.

[17] Gümüş, V. ve Kavşut, M.E., Zamanti Nehri-Ergenusağı İstasyonu Eksik Aylık Akım Verilerinin Tahmini. Gazi Üniversitesi Fen Bilimleri Dergisi Part C: Tasarım ve Teknoloji, 2013. 1(2): p. 8191. 
[18] Gümüş, V., Şimşek, O., Soydan, N.G., ve Kavşut, M.E. Estimation of Monthly Pan Evaporation Using Different Artificial Intelligence Methods in Kahramanmaraş Station. in 11th International Congress on Advances in Civil Engineering. 2014. İstanbul, Türkiye.

[19] Gümüş, V., Şİmşek, O., Soydan, N.G., Aköz, M.S., ve Yenİgün, K., Adana İstasyonunda Buharlaşmanin Farklı Yapay Zeka Yöntemleri ile Tahmini. Dicle Üniversitesi Mühendislik Dergisi, 2016. 7(2): p. 309-318.

[20] Gümüş, V., Başak, A., ve Oruç, N., Standartlaştırılmış Yă̆ış İndeksi (SYİ) Yöntemi ile Şanlıurfa İstasyonunun Kuraklık Analizi. Harran Üniversitesi Mühendislik Dergisi, 2016. 1(1): p. 36-44.

[21] Lippmann, R., An introduction to computing with neural nets. IEEE Assp magazine, 1987. 4(2): p. 422.

[22] Marquardt, D.W., An algorithm for least-squares estimation of nonlinear parameters. Journal of the society for Industrial and Applied Mathematics, 1963. 11(2): p. 431-441. 